\title{
Effectiveness of Caudal Epidural Block for Minor Gynaecological Procedures in Day Care Surgery
}

\author{
Ketaki Gayen ${ }^{1}$, Raj Sekhar Sarkar² \\ ${ }^{1}$ Department of Anaesthesiology, Nil Ratan Sircar Medical College and Hospital, Kolkata, West Bengal, India. ${ }^{2}$ Department \\ of Obstetrics and Gynaecology, Murshidabad Medical College and Hospital, Berhampur, West Bengal, India.
}

\section{ABSTRACT}

\section{BACKGROUND}

It is a well-known fact that caudal epidural block is effective in delivering paediatric analgesia, but the data regarding its usefulness for sacral analgesia and anaesthesia in adult patients is scarce. In this study, it is applied in teenage and adult patients in obstetric and gynaecological minor surgical procedures.

\section{METHODS}

179 female patients of ASA 1 and 2 of age group 11-70 yrs. undergoing minor gynaecological procedures were selected for this study. After pre anaesthetic checkup each patient was given $20 \mathrm{ml}$ of $1.5 \%$ Lignocaine with Adrenaline (1:200000) in caudal epidural space. The effectiveness of caudal epidural block was studied in terms of type and duration of surgery, sensory level of analgesia, success rate, use of rescue analgesics and postoperative complications during PACU stay.

\section{RESULTS}

The result of this study is overwhelming. The success rate is $97.21 \%$, only 5 patients required rescue analgesia with $2.79 \%$ failure rate. Average duration of anaesthesia and surgery were 36.4 mins and 22 mins respectively. Highest sensory level reached below T1W. Hypotension (6.14\%), retention of urine $(4.46 \%)$, persistent weak/heavy legs (3.91\%), sedative requirement (10.05\%),infection $(1.11 \%)$ and sacral hematoma $(0.55 \%)$ were among the side effects. $6.14 \%$ of patients had $>2 \mathrm{hrs}$. stay at recovery. It was observed that caudal analgesia is effective for minor gynaecological and obstetric procedures with no significant failure rate, complications and no fatality.

\section{CONCLUSIONS}

Caudal epidural block is an alternate and simple procedure when compared to SAB/TIVA for MGP with high success rate and lesser side effects with decreased duration of PACU stay. Caudal epidural block is not only effective in paediatric patients but also in teens and adults for minor perineal procedures.

\section{KEY WORDS}

Caudal, Epidural, Analgesia, Sacrococcygeal
Corresponding Author: Dr. Raj Sekhar Sarkar, 340/1, Banamali Banerjee Road, Haridebpur, Kolkata-700082, West Bengal, India.

E-mail:dr_rajsekhar@yahoo.in

DOI: $10.14260 / j e m d s / 2019 / 850$

Financial or Other Competing Interests: None.

How to Cite This Article: Gayen K, Sarkar RS. Effectiveness of caudal epidural block for minor gynaecological procedures in day care surgery. J. Evolution Med. Dent. Sci. 2019;8(52):3926-3931, DOI: $10.14260 /$ jemds $/ 2019 / 850$

Submission 16-09-2019,

Peer Review 12-12-2019,

Acceptance 20-12-2019,

Published 30-12-2019. 


\section{BACKGROUND}

In 1901, the first epidural anaesthesia via a caudal approach was independently described by two Frenchman Jean Anthanase Sicard and Fernand Cathelin. In recent years most surgeons as well as anaesthesiologists are giving stress on early discharge from hospital after OT as per ERAS protocol. This offers advantages both for the patient \& the health care facility. Although most of the surgeons as well as patients prefer general anaesthesia, regional anaesthetic techniques have also become popular in recent times owing to its increased safety and ease of administration.

Nerve supply of perineal region is by pudendal nerve (S 2, $3,4)$, which after entering the pudendal canal gives rise to the inferior rectal nerve and the perineal nerve and terminates as the dorsal nerve of penis (or clitoris).The pudendal nerve supplying the vagina and pelvic outlet is the main nerve we need to anaesthetise the pelvic region, also the Genitofemoral (L 1, 2) and perineal branch of posterior femoral nerve (L 2, 3, 4). The nerve supply to pelvis is autonomic sympathetic nerves from inferior hypogastric plexus (T10-L1) supply the uterus and cervix.

The sacral canal is continuity of lumbar epidural space. It contains the nerve roots of cauda equina which leave it through anterior sacral foramina. During caudal anaesthesia, leakage of local anaesthetic through these foramina explains the high quality of analgesia, attributable to diffusion of local anaesthetic along the nerve roots.

For minor gynaecological operations caudal block is sufficient for good analgesia, relaxation of perineal muscles and surgeons' comfort while doing the operations. Though the spread of analgesia cannot be enhanced above T8-T9 by increasing injected local anaesthetic volume, the relaxation up to that level is not required for minor gynaecological procedures.

The anticipated advantages of regional anaesthesia included less nausea vomiting, greater potential for postoperative analgesia, reduced risk of aspiration pneumonitis, reduced postoperative nursing overload and enhanced ability to communicate with the patient both intraop and postop.(1) Mingus stated that the most anaesthesiologists would prefer regional anaesthesia due to rapid recovery advantages in comparison with general anaesthesia.(2) There have been many studies about the use of caudal anaesthesia for paediatric patients. ${ }^{(3-8)}$ As for adult patients, the sacrum is the most variable bone which makes the sacral hiatus not easily identifiable in this region. ${ }^{(9)}$ Although it is much debated fact whether caudal block is effective in adult population or not, and there are only few studies in this regard, we have done an observational study on caudal block technique for MGP in day care surgery.

\section{Aims and Objectives}

1. To establish CEB can be used as a simple, safe and economic method of anaesthesia for adult patients undergoing minor gynaecological procedures.

2. To prove good quality of analgesia obtained during procedures.

3. Minimum amount of rescue analgesic requirement during and after the procedures.
4. That CEB has other advantages over subarachnoid block like post-dural puncture headache, intraoperative and postoperative bradycardia and hypotension, decreased blood loss, improved cardiac and pulmonary function, early ambulation and shortened duration of stay in post anaesthesia care unit (PACU).

5. Negligible postoperative complications like urinary retention as previously anticipated.

\section{METHODS}

This prospective interventional study was carried out in Gynae OT of different private hospitals in Behrampur and Kolkata during the period of Jan 2018 to June 2019 (1 1/2) years. The initial one year was used for data collection and the next six months for tabulation and analysis of the collected data. Anatomy, physiology and pharmacology related to the procedure are as follows:

\section{Anatomy}

The 5 sacral vertebra forms the convex dorsal roof of the caudal space and the base of sacrum forms the floor. Anatomically the space is approached via the sacral hiatus, which is formed by sacral cornua on either side. The sacrococcygeal ligament (extension of ligamentum flavum) overlies the sacral hiatus between the two sacral cornua. To facilitate locating the cornua, the posterior superior iliac spines should be located. By joining these two points forms the base of equilateral triangle and the apex is formed by the sacral hiatus. As the age advances the axis of the sacrum in relation to the lumbosacral spines changes and the hiatus is difficult to access as it often fuses. Moreover, the sacrococcygeal ligaments are tough or calcified making the procedure difficult in adult. The volume of sacral canal average $14.4 \mathrm{ml}$, but varies from 9.5 to $26.6 \mathrm{ml}$.

\section{Drugs and Dosage}

Single dose caudal epidural block $1.5 \%$ lignocaine $20 \mathrm{ml}$ with Adrenaline (1:200000)

\section{Armitage Formula}

Lignocaine max dose $7 \mathrm{mg} / \mathrm{Kg}$ without Adrenaline and 10 $\mathrm{mg} / \mathrm{Kg}$ with Adrenaline.

1. $0.5 \mathrm{ml} / \mathrm{Kg}$ for lumbosacral block.

2. $1 \mathrm{ml} / \mathrm{Kg}$ for thoracolumbar block.

3. $1.5 \mathrm{ml} / \mathrm{Kg}$ for mid thoracic block.

(Maximum of $20 \mathrm{ml}, 1 \%$ for analgesia and 2\% for motor block.)

\section{Pharmacology of Lignocaine}

Lignocaine is amide type local anaesthetic and class $1 \mathrm{~b}$ antiarrhythmic. In addition to its anaesthetic and anti-arrhythmic effects lignocaine has analgesic, anti-nociceptive, immunomodulatory and anti-inflammatory properties. Systemic name $=2-($ diethylamino $)-\mathrm{N}-(2,6-$ dimethylphenol $)$ acetamide. Molecular formula: $\mathrm{C} 14 \mathrm{H} 22 \mathrm{~N} 2 \mathrm{O}, \mathrm{HCl}, \mathrm{H} 2 \mathrm{O}$.

Mechanism of action: Lignocaine acts by reversible blockade of nerve fibres impulse propagation. Some is removed by tissue binding and circulation when Lignocaine is infiltrated near a nerve. The remaining enters the nerve cells by diffusion through membranes. Lignocaine binds to $\mathrm{Na}$ 
channels causing a conformational change that prevents the transient influx of sodium, therefore depolarisation sensory fibres are blocked preferentially as they are thinner and unmyelinated. Lignocaine onset of action is rapid, and quality of block depends on the dose given, concentration used, nerves blocked and status of patient-

- Pharmacokinetics $=70 \%$ bound to alfa 1 glycoprotein.

- Absorption depends on duration of application and surface area.

- Biotransformation $=90 \%$ hepatic.

- $\mathrm{T} 1 / 2=60-120$ mins.

- Therapeutic plasma concentration= $1.5-5 \mathrm{microgram} / \mathrm{ml}$.

- Duration of action=iv route 10-20 mins.

- Elimination=Renal excretion $10 \%$ unchanged.

- Systemic clearance 10-20 ml/min/Kg.

In the pre-anaesthetic check-up clinic, a detailed history was taken from each patient which included history of present and past illness, past history of any operation or anaesthetic exposure, history of drug intake or any allergy, any significant family history and history of addiction. A thorough general survey (Including body weight and height) was performed along with examinations of CVS, respiratory, genitourinary, gastrointestinal and CNS. Routine preoperative investigations for complete hemogram, coagulation profile, blood sugar, serum urea, creatinine, chest $\mathrm{x}$ ray and 12 lead resting ECG were performed and evaluated. 179 female patients in between age group 11-70 years belonging to ASA physical status 1 and 2 undergoing minor gynaecological procedures under caudal block were selected for study. The inclusion and exclusion criteria are as mentioned below.

\section{Inclusion Criteria}

1. Age group between 11-70 yrs.

2. ASA grade 1 and 2 patients.

3. Duration of surgery $<1$ hour.

\section{Exclusion Criteria}

1. History of allergic reactions to the drug in use.

2. Patients with morbid obesity (BMI more than 40); h/o sacral injury or deformity, sacral hiatus that was difficult to palpate, sepsis.

3. Patients with systemic, neurological, cardiac and respiratory disorders.

4. Patients with bleeding diathesis.

5. Patients refusing caudal block.

\section{Sample Size}

A total of 179 female patients were determined by power analysis based on a standard deviation data from a previous study report.

\section{Method of Data Collection}

Patients undergoing minor gynaecologic procedures were selected. On the day before surgery all patients included in the study were re-examined and advised for $8 \mathrm{hrs}$ fasting state preoperatively. Written informed consent was taken from all patients after explaining to them about caudal epidural block, nature of study and risks involved. All patients were given Tab Alprazolam $0.5 \mathrm{mg}$ and Tab Ranitidine $150 \mathrm{mg}$ orally at bedtime on previous night of surgery. On the day of surgery after confirmation of NPO status, patients were shifted to the operating room and connected to multipara monitor. Basal systolic blood pressure, diastolic blood pressure, mean arterial pressure, ECG and oxygen saturation were recorded. Continuous monitoring of vital parameters was done. An intravenous line was secured with an appropriately sized cannula. Preloading with $500 \mathrm{ml}$ of Ringer lactate over 30 mins was done to maintain adequate hydration. Patients were premedicated with iv Fentanyl 50 microgram and Midazolam $1 \mathrm{mg}$ for light sedation before blocks. Patient was turned to left lateral decubitus with thighs flexed at right angles to the hip. Antiseptic dressing and draping were done over the skin of sacrococcygeal area with povidone iodine. Once sacral hiatus is identified a short bevelled 22G needle is inserted at an angle of $45^{\circ}$ and advanced forward as the needle pierces the $1-2 \mathrm{~cm}$ in caudal canal. A small amount of LA ( $4 \mathrm{ml}$ ) was injected as test dose and perioral tingling or numbness or hypotension was looked for. Then $1.5 \%$ Lignocaine with Adrenaline (1:200000) $20 \mathrm{ml}$ is injected after negative aspiration for blood or CSF to exclude accidental intravascular or intrathecal insertion respectively. Care was taken to look for the signs of Local Anaesthesia Systemic Toxicity.

After successful block we positioned the patient carefully from lateral to supine and then to lithotomy position. Patient was given oxygen by nasal cannula @2 lit/min throughout the procedure. Confirmation of adequate block (sensory) was done by pinprick test 10 mins. after administering LA in Caudal epidural space. No other form of analgesia was used to augment the block height and quality. But during surgery when patient was complaining of pain the rescue doses of iv Fentanyl was given (defined as unsuccessful block).Successful block is defined as when whole surgery was done without any additional analgesia. When patient was able to flex the hip after completion of operation it was taken as recovery from motor block.

During operation monitoring was done on highest level of sensory anaesthesia, duration of block, SBP, DBP, MAP, pulse, SPO2. Other parameters that were considered were type and duration of gynaecological procedure, intraoperative bradycardia, hypotension, pruritus, LA systemic toxicity and postoperative complications (post dural puncture headache, urinary retention) and duration of stay in PACU. After OT patients were shifted to PACU and discharged after they fulfil Modified Aldrete Scoring System to the post-surgical ward.

\section{RESULTS}

The study group consisted of 179 female patients of age group 11-70 yrs. of ASA grade 1 and 2 undergoing minor gynaecological procedures. The patient's age distribution is shown in table 1, types of surgery are shown in table 2 .

\begin{tabular}{|c|c|c|}
\hline Age & Number of Patients & Percentage \\
\hline $11-20$ & 18 & $10.05 \%$ \\
\hline $21-30$ & 23 & $12.84 \%$ \\
\hline $31-40$ & 46 & $25.69 \%$ \\
\hline $41-50$ & 47 & $26.29 \%$ \\
\hline $51-60$ & 28 & $15.64 \%$ \\
\hline $61-70$ & 17 & $9.49 \%$ \\
\hline \multicolumn{3}{|c|}{ Table 1. Age Distribution } \\
\hline
\end{tabular}




\begin{tabular}{|c|c|}
\hline Gynaecological Operations & Number of Cases \\
\hline Hymenectomy & 09 \\
\hline Dilatation and Curettage & 60 \\
\hline Cervical Cautery & 25 \\
\hline Repair of Vaginal Injury (Coital) & 07 \\
\hline Vulval Biopsy & 15 \\
\hline Simple Vulvectomy & 05 \\
\hline Repair of 3* and 4* Perineal Tear & 22 \\
\hline Posterior Colpoperineorrhaphy & 10 \\
\hline Obstetric Operations & 08 \\
\hline Encirclage (McDonald) & 18 \\
\hline Episiotomy Repair & Number of Cases \\
\hline Table 2. Types of Operations \\
\hline
\end{tabular}

\begin{tabular}{|c|c|c|c|c|c|c|c|c|c|c|}
\hline 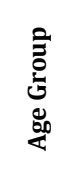 & 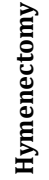 & u & $\begin{array}{l}\vec{d} \\
\stackrel{\vec{U}}{\pi}\end{array}$ & 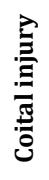 & 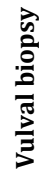 & 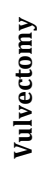 & 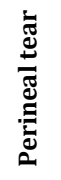 & 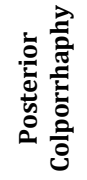 & 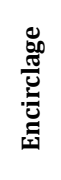 & 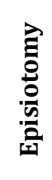 \\
\hline $11-20$ & 9 & & & 3 & & & 4 & & & 8 \\
\hline $21-30$ & & & & 4 & & & & & 6 & 10 \\
\hline $31-40$ & & 50 & 10 & & & & 18 & 2 & 2 & \\
\hline $41-50$ & & 10 & 15 & & & & & 8 & & \\
\hline $51-60$ & & & & & 5 & & & & & \\
\hline 61-70 & & & & & 10 & 5 & & & & \\
\hline \multicolumn{11}{|c|}{ Table 3. Types of Operations According to Age } \\
\hline
\end{tabular}

\begin{tabular}{|c|c|c|c|c|}
\hline $\begin{array}{c}\text { Sl. } \\
\text { No. }\end{array}$ & $\begin{array}{c}\text { Common Side } \\
\text { Effects }\end{array}$ & $\begin{array}{c}\text { With Side } \\
\text { Effects }\end{array}$ & $\begin{array}{c}\text { Without Side } \\
\text { Effects }\end{array}$ & $\begin{array}{c}\text { \% of Patients } \\
\text { with Side Effects }\end{array}$ \\
\hline 1 & $\begin{array}{c}\text { Persistent weak/heavy } \\
\text { legs ( }>3 \text { hrs.) }\end{array}$ & 7 & 172 & $3.91 \%$ \\
\hline 2 & Inadequate pain relief & 5 & 174 & $2.79 \%$ \\
\hline 3 & Retention of urine & 8 & 171 & $4.46 \%$ \\
\hline 4 & Hypotension & 11 & 168 & $6.14 \%$ \\
\hline 5 & Headache & 3 & 176 & $1.67 \%$ \\
\hline 6 & Sedation & 18 & 161 & $10.05 \%$ \\
\hline 7 & Itching & 0 & 179 & $0 \%$ \\
\hline 8 & Nerve damage & 0 & 179 & $0 \%$ \\
\hline 9 & Infection & 2 & 177 & $1.11 \%$ \\
\hline 10 & Hematoma & 1 & 178 & $0.55 \%$ \\
\hline \multicolumn{5}{|c|}{ Table 4. Common Side Effects } \\
\hline
\end{tabular}

\begin{tabular}{|c|c|c|c|}
\hline Sl. No. & No. of Patients & \% of Patients \\
\hline 1 & Failure of anaesthesia & 5 & $2.79 \%$ \\
\hline 2 & $>2$ hrs. stay at recovery & 11 & $6.14 \%$ \\
\hline 3 & Increased hospital stay & & $7.26 \%$ \\
\hline & a)due to anaesthesia & 13 & $5.58 \%$ \\
\hline & b)due to surgery & 10 & $0.55 \%$ \\
\hline 4 & Life threatening complications & 1 & $1.11 \%$ \\
\hline & a)Due to anaesthesia & 2 & $0 \%$ \\
\hline & b)Due to surgery & 0 & $0 \%$ \\
\hline 5 & Fatality & 0 & \\
\hline \multicolumn{3}{|c|}{ Table 5. Uncommon Side Effects } \\
\hline & a)Due to anaesthesia & & \\
\hline
\end{tabular}

Anaesthesia duration included the time for antiseptic dressing and draping, performing caudal block, patient positioning after the block and sterilization of operative field. All patients were given light sedation before block and overall success rate of caudal block is $97.21 \%$. The sensory level in all patients reached below T12. Majority of our gynaecological operations were dilatation and curettage which included 60 cases, followed by repair of $3^{\text {rd }}$ degree and $4^{\text {th }}$ degree perineal tear and others. Among obstetric operations majority were episiotomy repair. Our majority patient pool was in 31-50 years age group. Among the common side effects 7 patients (3.91\%) had persistent weak or heavy legs. Hypotension was an uncommon finding in only $(6.14 \%)$ of patients unlike subarachnoid block. There was failure of anaesthesia in 5 individuals $(2.79 \%)$ in whom there was inadequate pain relief and so rescue analgesics were given. Sedatives were required in 18 individuals $(10.05 \%)$ who were anxious and also due to failed block. Caudal block has a common side effect of retention of urine. 8 patients $(4.46 \%)$ reported this. There was sacral hematoma in 1 patient $(0.55 \%)$ and infection in 2 patients $(1.11 \%)$. None of the patients experienced itching or nerve damage. Recovery of lower limb power, tone and regaining of consciousness was the parameter for discharge from PACU.11 patients (6.14\%) had $>2$ hrs. stay at recovery. Due to over sedation in 5 patients and delayed urination in 8 patients, total of 13 patients (7.26\%) had increased hospital stay. This was mainly seen in 61-70 yrs. of age group patients. 10 patients $(5.56 \%)$ undergoing $3^{\text {rd }}$ and $4^{\text {th }}$ degree perineal tear and posterior colpoperineorrhaphy had increased duration of stay in PACU. Only 1 patient $(0.55 \%)$ had convulsion which was may be due to intravascular injection of lignocaine and adrenaline which was managed by iv Lorazepam and 2 patients (1.11\%) had secondary haemorrhage due to surgery. None of the patients had fatal outcome from caudal epidural block. No special unpleasant or distressing symptoms were reported on the follow-up appointments.

\section{DISCUSSION}

The primary mechanism of caudal epidural anaesthesia is the spinal nerve root block. It is a simple and quickly done procedure, allowing short turnover time while providing good surgical anaesthesia and postoperative analgesia. Caudal epidural block is frequently used for abdominal surgery in neonates and is probably the most frequently used regional anaesthetic techniques in neonates and infants. But our aim of study was whether caudal epidural block can be used as a simple safe and economic method of anaesthesia for adult patients undergoing minor gynaecological procedures. Some authors reported that caudal anaesthesia was a useful technique for minor anal surgery.(10,11) Abouleish also stated that caudal epidural block was used safely as a labouring analgesia (12).In Taiwan, Chen et al(13) first reported the use of caudal block during a vaginal delivery. But our study was mainly confined to minor gynaecological operations in perineal area which only require anaesthesia in lumbosacral area which may be done by local anaesthesia alone. Most of the patients had apprehension regarding the caudal block so to make them comfortable light sedation in the form of Fentanyl (50 microgram) and Midazolam (1 mg) was given before the block was performed. In the report by Crighton, there was $10 \%$ rate of technical failure because of an absent sacral hiatus due to wide anatomic variations in these regions.(9) So a careful patient selection $(\mathrm{BMI}<35)$,preoperative explanation of the procedure during PAC and premedication to allay the anxiety is considered mandatory. Moreover, performance of the block with accurate and correct needle insertion(14,15) by experienced and skilled anaesthesiologist results in high success rate of the block (97.21\%). In our study only 5 patients $(2.79 \%)$ had inadequate pain relief due to failure of the block and required rescue analgesia. One patient had intravascular injection of Lignocaine and Adrenaline and so experienced convulsion which was managed with iv Lorazepam and 100\% oxygen supplementation. 7 of the patients had persistent leg weakness and paraesthesia. The use of different local 
anaesthetics (Lignocaine, Mepivacaine, Bupivacaine or Ropivacaine) and the addition of caudal adjuvant (e.g. Adrenaline, Clonidine, Ketamine, Neostigmine, narcotics or alkalization with sodium bicarbonate) ${ }^{(16-22)}$ must be evaluated for their efficacy and drug effects. All of these factors affect the level of analgesia, onset of action and duration of sensory and/or motor blockade. Different concentrations of $1 \%$, $1.5 \%$, and $2 \%$ ) of lidocaine had been studied.(23,24) A high concentration of lidocaine produced a more intense sensory and motor blockade.(22) The addition of additives accelerated the onset and block was more profound with longer lasting effects. But we did not use any caudal additives in our study. The common side effects of subarachnoid block like hypotension, bradycardia was seen in few patients. Hypotension was mainly due to iv sedatives before block which was corrected by giving intravenous fluid. Other side effects of subarachnoid block like paraplegia, cauda-equina syndrome, nerve injury, cardiac arrest, respiratory depression, nausea, vomiting, pruritus, PDPH were not seen. Urinary retention was seen in $4.46 \%$ of patients. Drug dose was calculated according to Armitage formula, which was 15$20 \mathrm{ml}$ for blocks of lower limb and perineum.(25) We deliberately used lower dose of local anaesthetics for doing MGP as the average surgical duration was $(<1 \mathrm{hr})$ and we required early ambulation and early discharge from PACU. When compared to TIVA caudal block is superior as fast track caudal anaesthesia allows short term postoperative surveillance or nursing care and reduces operation theatre pollution due to inhalational anaesthesia. With rapid patient ambulation and decreased postoperative analgesia requirements and nausea vomiting, it is also cost effective. In our study only 18 patients required postoperative narcotics and thus had increased duration of PACU stay. Hence the use of CEB may reduce the overall intake of medications, recovery unit resources and facility costs. 8 of our patients had postoperative retention of urine although in a retrospective study by Pappas et al (26) it was stated that caudal anaesthesia had no definitive correlation with postoperative urinary retention.

In our observational study the caudal epidural block is better than subarachnoid block or TIVA in terms of simplicity, rapid onset and recovery from it with less side effects (Hypotension, bradycardia, cardiac and respiratory depression, neurodeficit) for MGP without increasing the length of PACU stay.

\section{CONCLUSIONS}

Caudal epidural block is an alternate and simple procedure when compared to sub arachnoid block or TIVA for MGP with high success rate and lesser side effects with decreased duration of PACU stay.

\section{REFERENCES}

[1] Bridenbaugh LD. Regional anaesthesia for outpatient surgery-a summary of 12 years' experience. Can Anaesth Soc J 1983;30(5):548-52.
[2] Mingus ML. Recovery advantages of regional anaesthesia compared with general anaesthesia: adult patients. J Clin Anesth 1995;7(7):628-33.

[3] Cucchiaro G, De Lagausie P, El-Ghonemi A, et al. Singledose caudal anaesthesia for major intra-abdominal operations in high-risk infants. Anesth Analg 2001;92(6):1439-41.

[4] Karmakar MK, Aun CST, Wong ELY, et al. Ropivacaine undergoes slower systemic absorption from the caudal epidural space in children than bupivacaine. Anesth Analg 2002;94(2):259-65.

[5] Verghese ST, Mostello LA, Patel RI, et al. Testing anal sphincter tone predicts the effectiveness of caudal analgesia in children. Anesth Analg 2002;94(5):1161-4.

[6] Tobias JD. Caudal epidural block: a review of test dosing and recognition of systemic injection in children. Anesth Analg 2001;93(5):1156-61.

[7] Koinig H, Krenn CG, Glaser C, et al. The dose-response of caudal ropivacaine in children. Anesthesiology 1999;90(5):1339-44.

[8] Verghese ST, Hannallah RS, Rice LJ, et al. Caudal anaesthesia in children: effect of volume versus concentration of bupivacaine on blocking spermatic cord traction response during orchiopexy. Anesth Analg 2002;95(5):1219-23.

[9] Crighton IM, Barry BP, Hobbs GJ. A study of the caudal space using magnetic resonance imaging. $\mathrm{Br} J$ Anaesth 1997;78(4):391-5.

[10] Adebamowo CA, Ladipo JK, Ajao OG. Randomized comparison of agents for caudal anaesthesia in anal surgery. Br J Surg 1996;83(3):364-5.

[11] Van Elstraete AC, Lebrun T, Pastureau F. Costs and profiles of caudal anaesthesia for anorectal surgery in adults. Anesthesiology 2001;95(3):813-4.

[12] Abouleish E. Caudal analgesia for quadruplet delivery. Anesth Analg 1976;55(1):61-6.

[13] Chen JS, Lau HP, Chao CC. Caudal block in vaginal delivery. Ma Zui Xue Za Zhi 1987;25(3):145-50.

[14] Atherton AMJ. Caudal epidurals: the 'whoosh test'. Anaesthesia 1998;53:927.

[15] Tsui BCH, Tarkkila P, Gupta S, et al. Confirmation of caudal needle placement using nerve stimulation. Anesthesiology 1999;91(2):374-8.

[16] Curatolo M, Peterson-Felix S, Arendt-Nielsen L, et al. Adding sodium bicarbonate to lidocaine enhances the depth of epidural blockade. Anesth Analg 1998;86(2):341-7.

[17] Van Elstraete AC, Pastureau F, Lebrun T, et al. Caudal clonidine for postoperative analgesia in adults. $\mathrm{Br} \mathrm{J}$ Anaesth 2000;84(3):401-2.

[18] De Beer DA, Thomas ML. Caudal additives in children solutions or problems? Br J Anaesth 2003;90(4):487-98.

[19] Lawhorn CD, Stoner JM, Schmitz ML, et al. Caudal epidural butorphanol plus bupivacaine versus bupivacaine in pediatric outpatient genitourinary procedures. J Clin Anesth 1997;9(2):103-8.

[20] Constant I, Gall O, Gouyet L, et al. Addition of clonidine or fentanyl to local anesthetics prolong the duration of surgical analgesia after single shot caudal block in children. Br J Anaesth 1998;80(3):294-8. 
[21] Turan A, Memis D, Basaran UN, et al. Caudal ropivacaine and neostigmine in pediatric surgery. Anesthesiology 2003;98(3):719-22.

[22] Arakawa M, Aoyama Y, Ohe Y. Block of the sacral segments in lumbar epidural anaesthesia. $\mathrm{Br} J$ Anaesth 2003;90(2):173-8.

[23] Sakura S, Sumi M, Kushizaki H, et al. Concentration of lidocaine affects intensity of sensory block during lumbar epidural anaesthesia. Anesth Analg 1999;88(1):123-7.
[24] Yokoyama M, Mizobuchi S, Nagano 0, et al. The effects of epidural insertion site and surgical procedure on plasma lidocaine concentration. Anesth Analg 2001;92(2):470-5.

[25] Vadodaria B, Conn D. Caudal epidural anaesthesia. Update in Anaesthesia 1998;8:14-7.

[26] Pappas ALS, Sukhani R, Hatch D. Caudal anaesthesia and urinary retention for ambulatory surgery. Anesth Analg 1997;85(3):706. 